1 Supplement of

2

3 Characterization and source apportionment of aerosol light

4 scattering in a typical polluted city in Yangtze River Delta, China

5

6 Dong Chen, Yu Zhao, Jie Zhang, Huan Yu, Xingna Yu

7 *Corresponding author: Yu Zhao (yuzhao@nju.edu.cn)

8 
Table S1. The hygroscopic growth factors (GF) of particles at different particle sizes and RH levels in Nanjing from previous studies (Li et al., 2015; Wu, 2014; Xu et al., 2015; Yu et al., 2015; Zhang et al., 2011).

Table S2. The source apportionment of the primary and secondary aerosols for accumulation mode particles at NJU (Unit: \%).

Table S3. The same as Table S2 but for PAES.

Table S4. The same as Table S2 but for NUIST.

Table S5 The contributions of chemical components to the light scattering for accumulation mode particles based on the Mie theory (Unit: \%).

\section{Figure list}

Figure S1. The locations of NJU, PAES and NUIST sites in Nanjing. The map data provided by (C) Google (Google Earth) are freely available for academic use (http://www.google.cn/intl/zh-CN/earth/).

Figure S2. The size distribution of mass concentrations of particles and their main chemical components for the three pollution level periods.

Figure S3. The relationship between the reconstructed and measured PM mass concentrations at the three sites.

Figure S4. The size distribution of mass concentrations of particles and their main chemical components at NJU, PAES and NUIST.

Figure S5. Linear regressions between the measured daily scattering coefficients and those calculated with the IMPROVE1999 algorithm (a) and the IMPROVE2007 algorithm (b) at the three sites.

Figure S6. Linear regressions between the mass scattering efficiencies (MSE) of $\mathrm{NH}_{4} \mathrm{NO}_{3}(\mathrm{a})$ and $\left(\mathrm{NH}_{4}\right)_{2} \mathrm{SO}_{4}$ (b) estimated with the Mie theory and those with the two version of US IMPROVE algorithms.

Figure S7. Hygroscopic growth curve of $\mathrm{PM}_{2.5}$ at NJU. 
37 Figure S8. The correlation between the scattering coefficients estimated by $\mathrm{f}(\mathrm{RH})$ and 38 those simulated with Mie theory under the ambient conditions.

39 Figure S9. The comparison of the observed scattering coefficients and those estimated 40 with the external, internal, core-shell mixture assumption under the ambient condition 41 at NJU.

42 Figure S10. The box plots of the ratios of light absorption $\mathrm{BrC}$ mass to the total $\mathrm{BrC}$ 43 mass under the three pollution levels. The box plots indicate the mean concentration 44 (square symbols) and the maximum, 99th, 75th, 50th, 25th, 1st percentiles, and 45 minimum. Figure S11. The source profiles for accumulation mode particles from the PMF model 47 at NJU (a), PAES (b) and NUIST (c). 


\section{A1. IMPROVE1999 and IMPROVE2007 algorithms}

The $\mathrm{PM}_{2.5}$ scattering coefficient could be calculated with two IMPROVE algorithms, as described in Pitchford et al. (2007). Briefly, the IMPROVE1999 and IMPROVE2007 algorithms are expressed with Eqs. (S1) and (S2), respectively:

$b_{\text {sca }} \approx 3 \times f(R H)[$ Sulfate $]+3 \times f(R H)[$ Nitrate $]+4 \times[$ Organic Mass $]$

$+1 \times[$ Fine soil $]$

$b_{\text {sca }} \approx 2.2 \times f_{s}(R H)[$ Small Sulfate $]+4.8 \times f_{L}(R H)[$ Larg e Sulfate $]$

$+2.4 \times f_{s}(R H)[$ Small Nitrate $]+5.1 \times f_{L}(R H)[$ L arg e Nitrate $]$

$+2.8 \times[$ Small Organic Mass $]+6.1 \times[L$ arg e Organic Mass $]$

$+1 \times[$ Fine soil $]+1.7 \times f_{S S}(R \mathrm{H})[$ Sea salt $]$

The four major components in Eq. (S1) are sulfate (assumed to be $\left(\mathrm{NH}_{4}\right)_{2} \mathrm{SO}_{4}$ ), nitrate (assumed to be $\mathrm{NH}_{4} \mathrm{NO}_{3}$ ), organic mass (assumed to be organic compounds), and fine soil (crustal elements plus oxides). The $\mathrm{PM}_{2.5}$ scattering coefficient can be thus estimated by multiplying the concentrations of the four chemical components by typical component-specific mass scattering efficiencies. $f(R H)$ denotes the water growth terms for sulfate and nitrate.

IMPROVE2007 separates the large and small particle modes for sulfate, nitrate and OM using a simple mixing model, and different mass scattering efficiencies are used for the two modes (Eq. (S2)). With an assumption of log-normal mass size distribution, the large and small modes are described by the $\mathrm{D}_{\mathrm{g}}$ and geometric standard deviations $\left(\sigma_{\mathrm{g}}\right)$ at $0.5 \mu \mathrm{m}$ and 1.5, and $0.2 \mu \mathrm{m}$ and 2.2, respectively. Empirically, the fraction of each particle component in the large mode can be calculated by dividing the total concentration of the component by $20 \mu \mathrm{g} / \mathrm{m}^{3}$. If the concentration is above $20 \mu \mathrm{g} / \mathrm{m}^{3}$, all the mass is considered to be in the large mode. A sea salt term is added as a particular concern for coastal monitoring sites. The water growth curves for sea salt and the large and small particle modes of sulfate and nitrate can be referred to Pitchford et al. (2007). 
Tables

77 Table S1. The hygroscopic growth factors (GF) of particles at different particle 78 sizes and RH levels in Nanjing from previous studies ( $\mathrm{Li}$ et al., 2015; Wu, 2014;

79 Xu et al., 2015; Yu et al., 2015; Zhang et al., 2011).

\begin{tabular}{ccccc}
\hline $\mathrm{RH}(\%)$ & $80 \mathrm{~nm}$ & $130 \mathrm{~nm}$ & $200 \mathrm{~nm}$ & $398 \mathrm{~nm}$ \\
\hline 50 & 1.03 & 1.03 & 1.04 & 1.04 \\
60 & 1.03 & 1.05 & 1.04 & 1.04 \\
73 & 1.12 & 1.14 & 1.14 & 1.11 \\
77 & 1.17 & 1.19 & 1.18 & 1.12 \\
82 & 1.25 & 1.28 & 1.28 & 1.23 \\
85 & 1.28 & 1.34 & 1.35 & 1.28 \\
88 & 1.31 & 1.41 & 1.39 & 1.31 \\
90 & 1.41 & 1.45 & 1.49 & 1.27 \\
\hline
\end{tabular}


Table S2. The source apportionment of the primary and secondary aerosols for accumulation mode particles at NJU (Unit: \%).

\begin{tabular}{|c|c|c|c|c|c|c|c|}
\hline \multirow[b]{2}{*}{ Source } & \multirow[b]{2}{*}{$\begin{array}{c}\text { Primary apportionment } \\
\text { by PMF } \\
\end{array}$} & \multicolumn{5}{|c|}{ Secondary aerosol allocation } & \multirow[b]{2}{*}{ Total } \\
\hline & & Sector category & $\begin{array}{c}\text { Proportions of } \\
\mathrm{SO}_{2} \text { and } \mathrm{NO}_{2} \text { emissions }\end{array}$ & $\begin{array}{l}\text { Proportion } \\
\text { of SIA }\end{array}$ & $\begin{array}{c}\text { Proportion } \\
\text { of VOCs }\end{array}$ & $\begin{array}{l}\text { Proportion } \\
\text { of SOA }\end{array}$ & \\
\hline \multirow[t]{4}{*}{ Coal combustion } & 21.5 & Power plants & 41.5 & 10.9 & & & 32.3 \\
\hline & & Chemical industry & 13.0 & 3.4 & 49.0 & 1.5 & \\
\hline & & Steel industry & 13.0 & 3.4 & 10.0 & 0.3 & \\
\hline & & Cement industry & 7.0 & 1.8 & - & & \\
\hline \multirow{3}{*}{ Industrial pollution } & 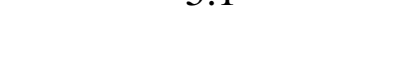 & Coating industry & - & & 11.0 & 0.3 & 10.0 \\
\hline & & Other industrial solvent & - & & 5.0 & 0.2 & \\
\hline & & Other industries & 3.0 & 0.8 & - & & \\
\hline Vehicle & 21.0 & On road vehicle & 12.0 & 3.1 & 10.0 & 0.3 & 24.4 \\
\hline Fugitive dust & 18.4 & - & - & & - & & 18.4 \\
\hline Biomass burning & 4.9 & - & 0.7 & 0.2 & 1.4 & 0.0 & 5.1 \\
\hline Others & & - & 9.8 & 2.6 & 13.6 & 0.4 & 3.0 \\
\hline Total & 70.8 & - & 100.0 & 26.2 & 100.0 & 3.0 & 100.0 \\
\hline
\end{tabular}


Table S3. The same as Table S2 but for PAES.

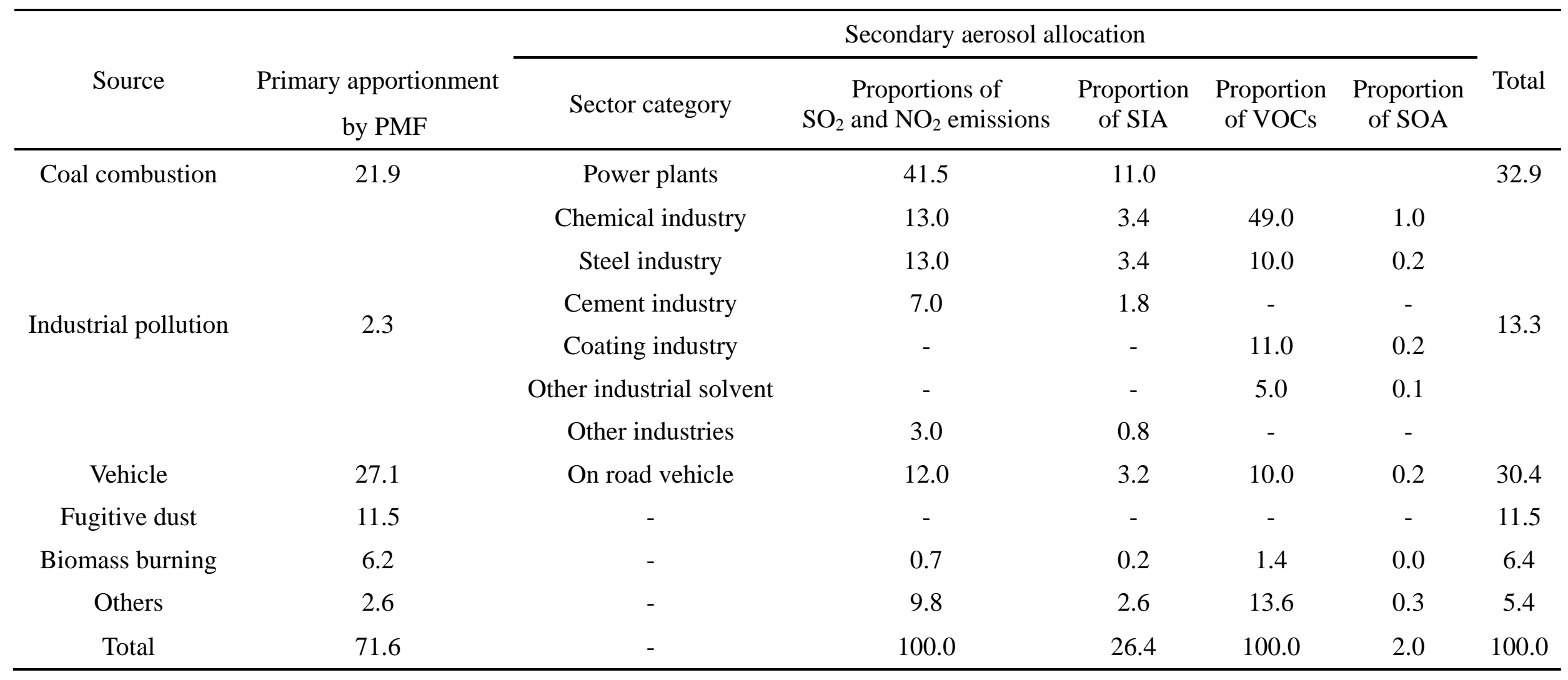


Table S4. The same as Table S2 but for NUIST.

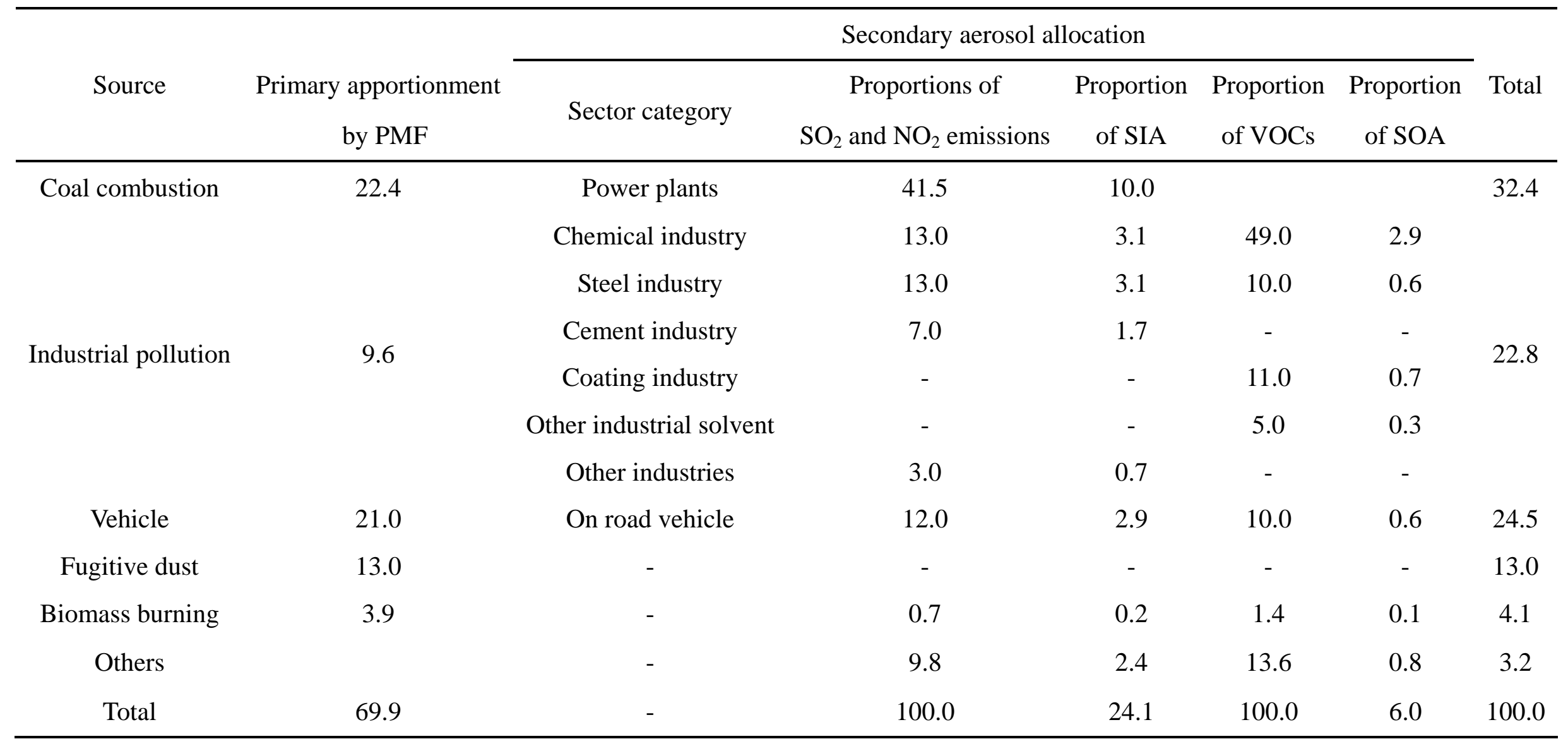


Table S5. The contributions of chemical components to the light scattering for accumulation mode particles based on the Mie theory (Unit: \%).

\begin{tabular}{ccccc}
\hline Locations & $\left(\mathrm{NH}_{4}\right)_{2} \mathrm{SO}_{4}$ & $\mathrm{NH}_{4} \mathrm{NO}_{3}$ & $\mathrm{OM}$ & others \\
\hline NJU & 24.3 & 25.5 & 31.0 & 16.6 \\
PAES & 21.3 & 23.6 & 29.4 & 23.1 \\
NUIST & 25.8 & 18.7 & 32.9 & 20.4 \\
\hline
\end{tabular}




\section{Figures}

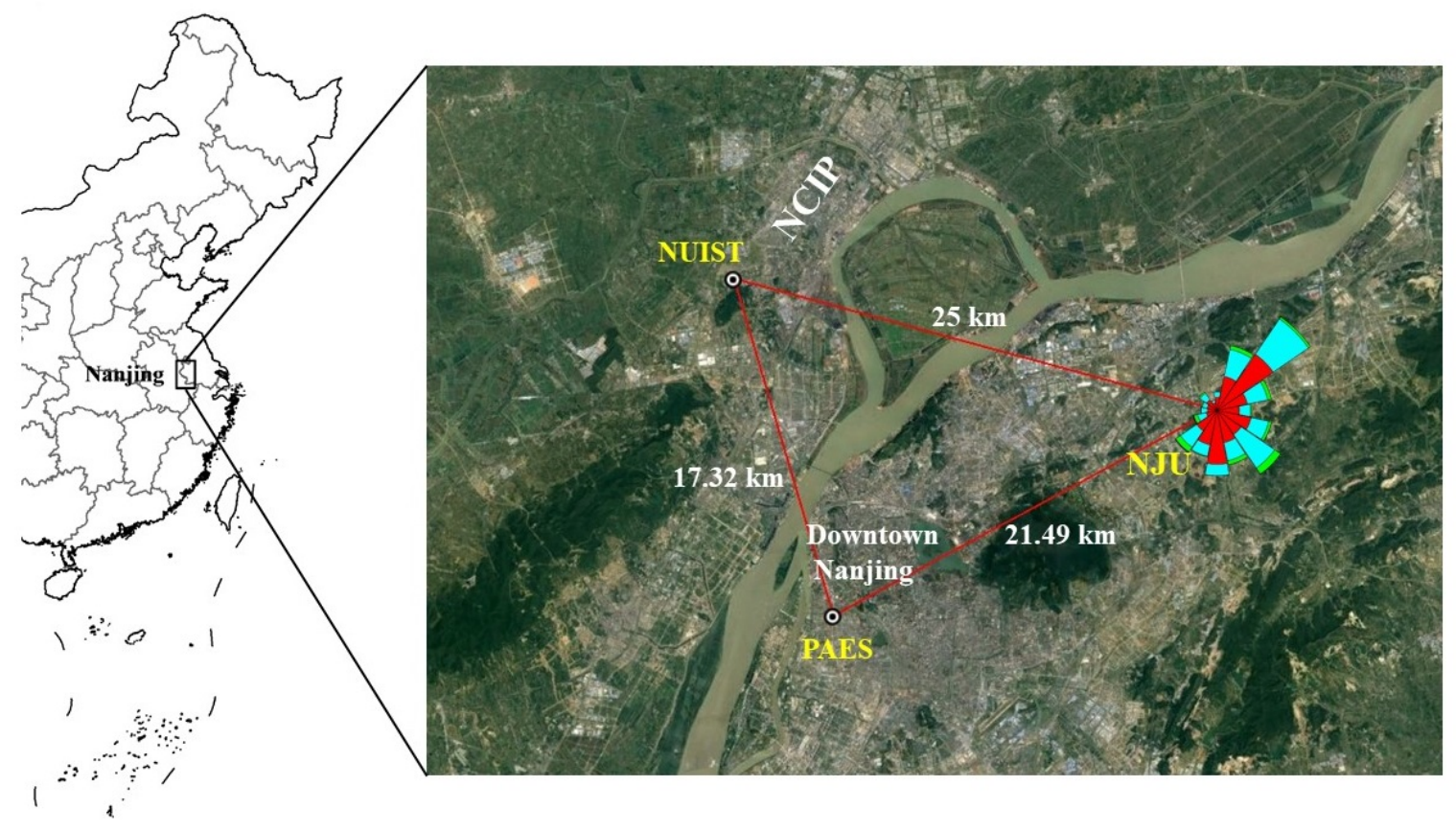

Figure S1. The locations of NJU, PAES and NUIST sites in Nanjing. The map data provided by (C) Google (Google Earth) are freely available for academic use (http://www.google.cn/intl/zh-CN/earth/). 

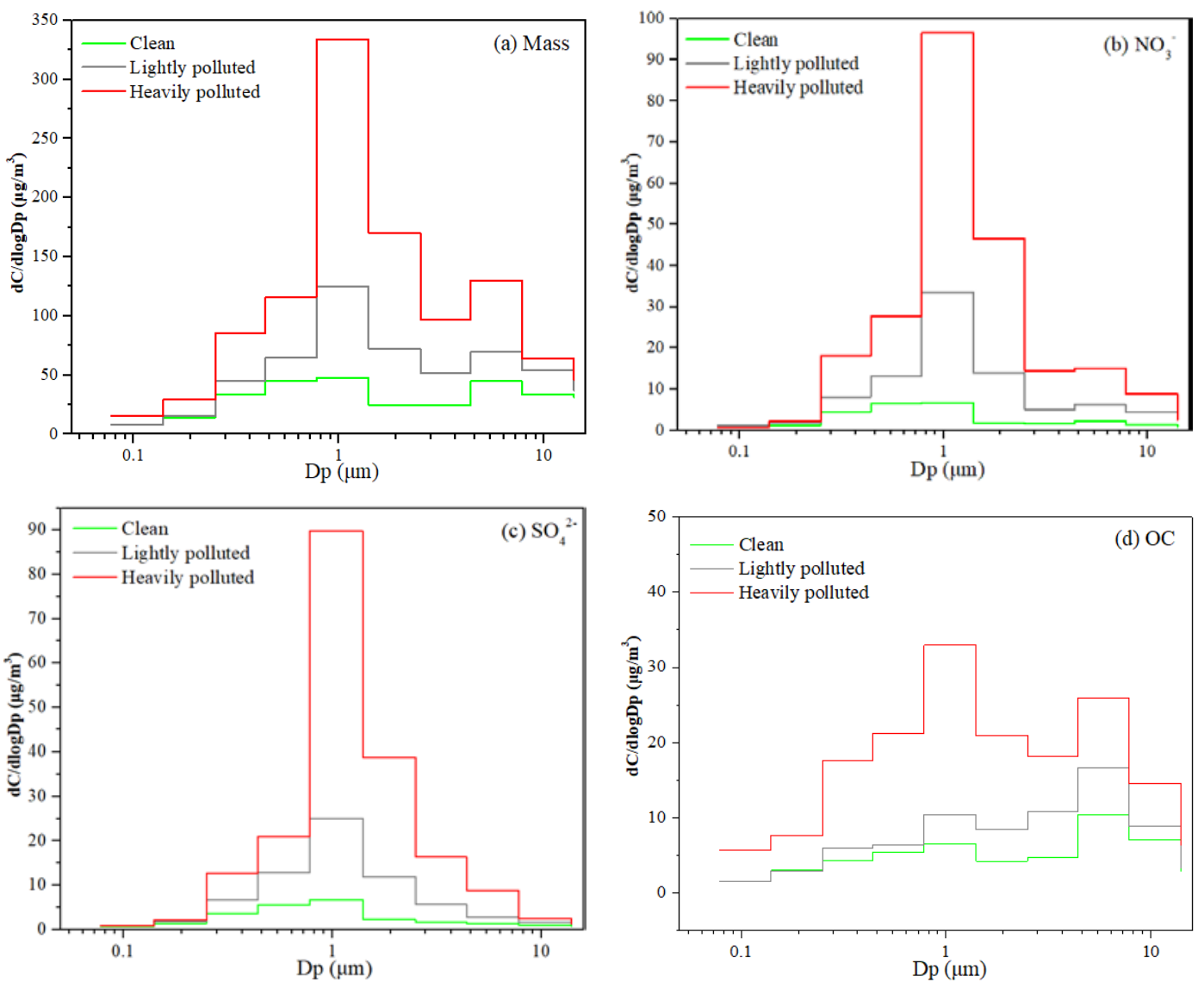

Figure S2. The size distribution of mass concentrations of particles and their main chemical components for the three pollution level periods. 


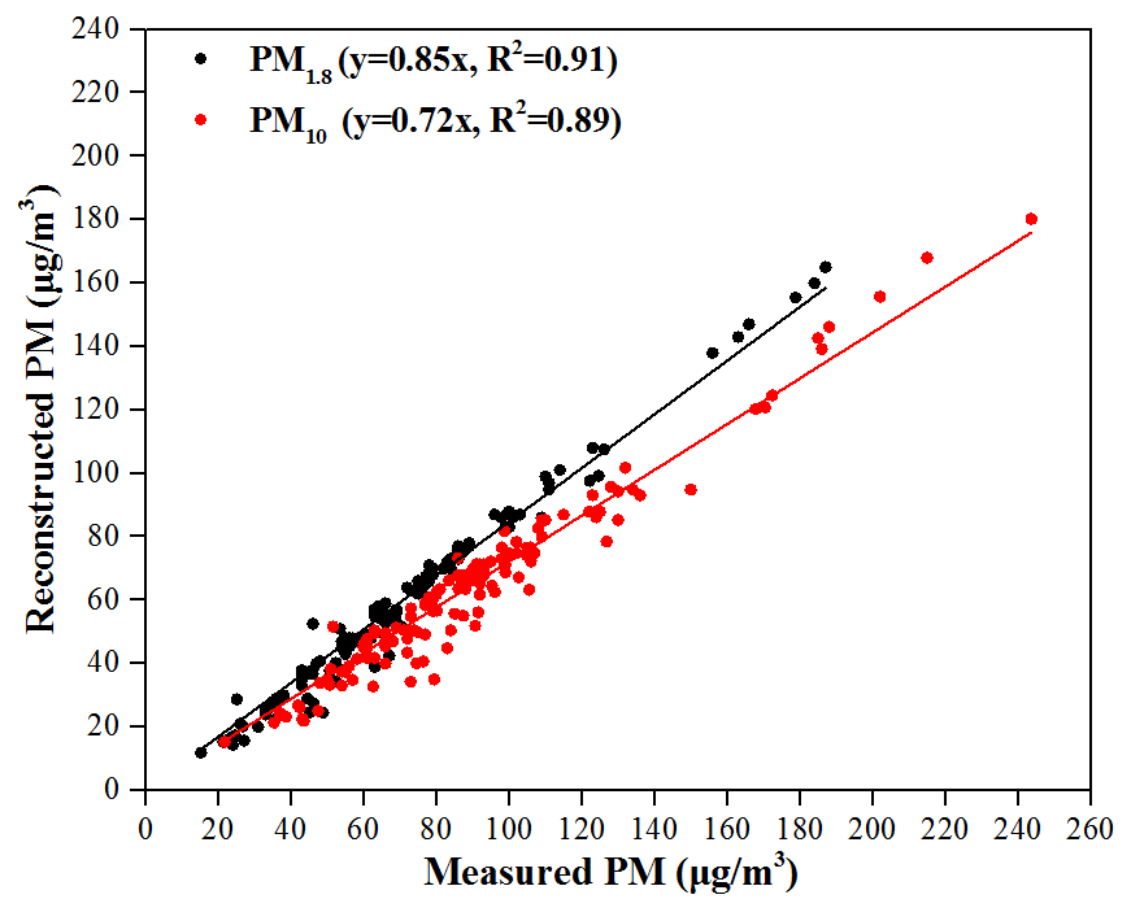

Figure S3. The relationship between the reconstructed and measured PM mass concentrations at the three sites. 

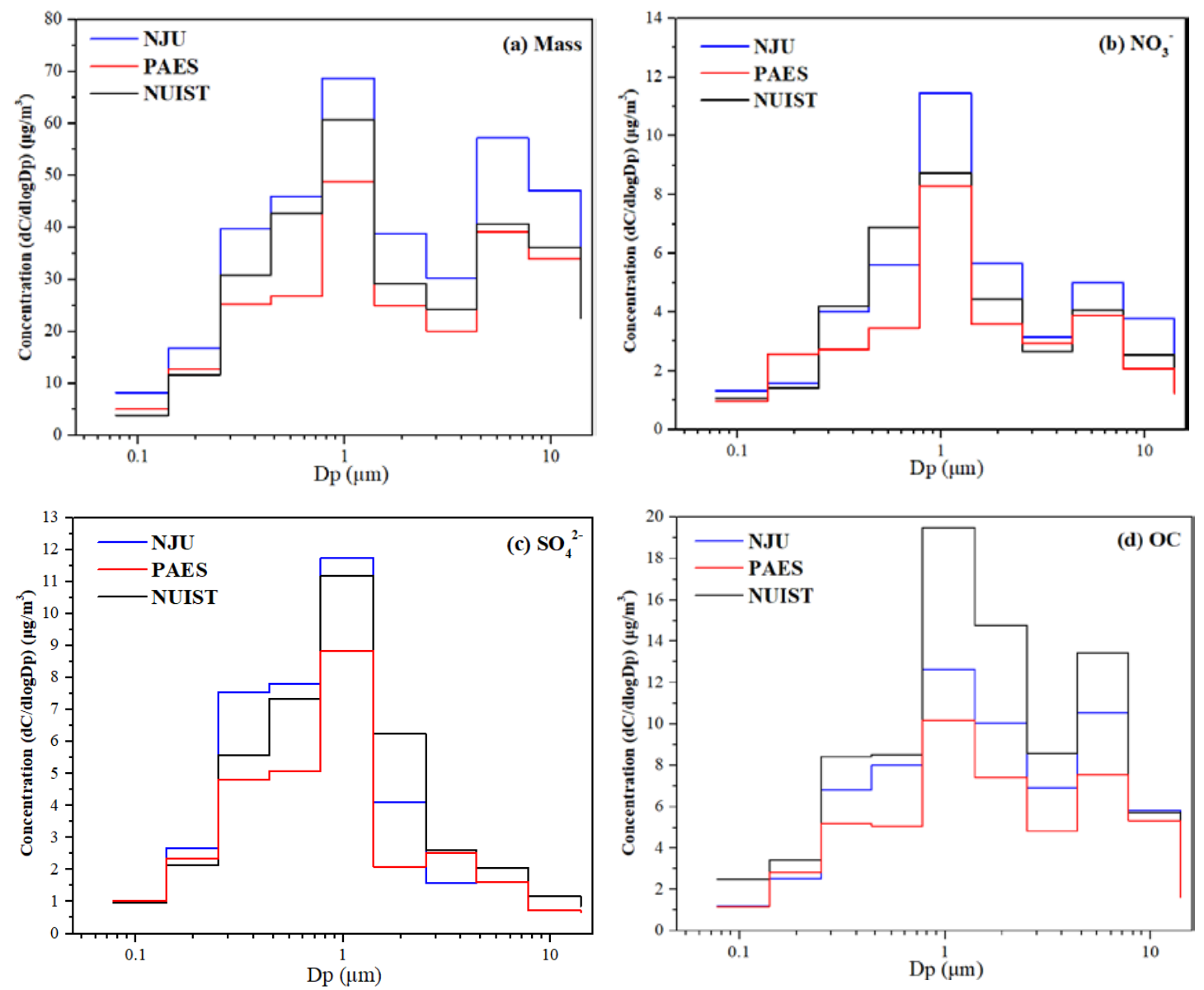

Figure S4. The size distribution of mass concentrations of particles and their main chemical components at NJU, PAES and NUIST. 

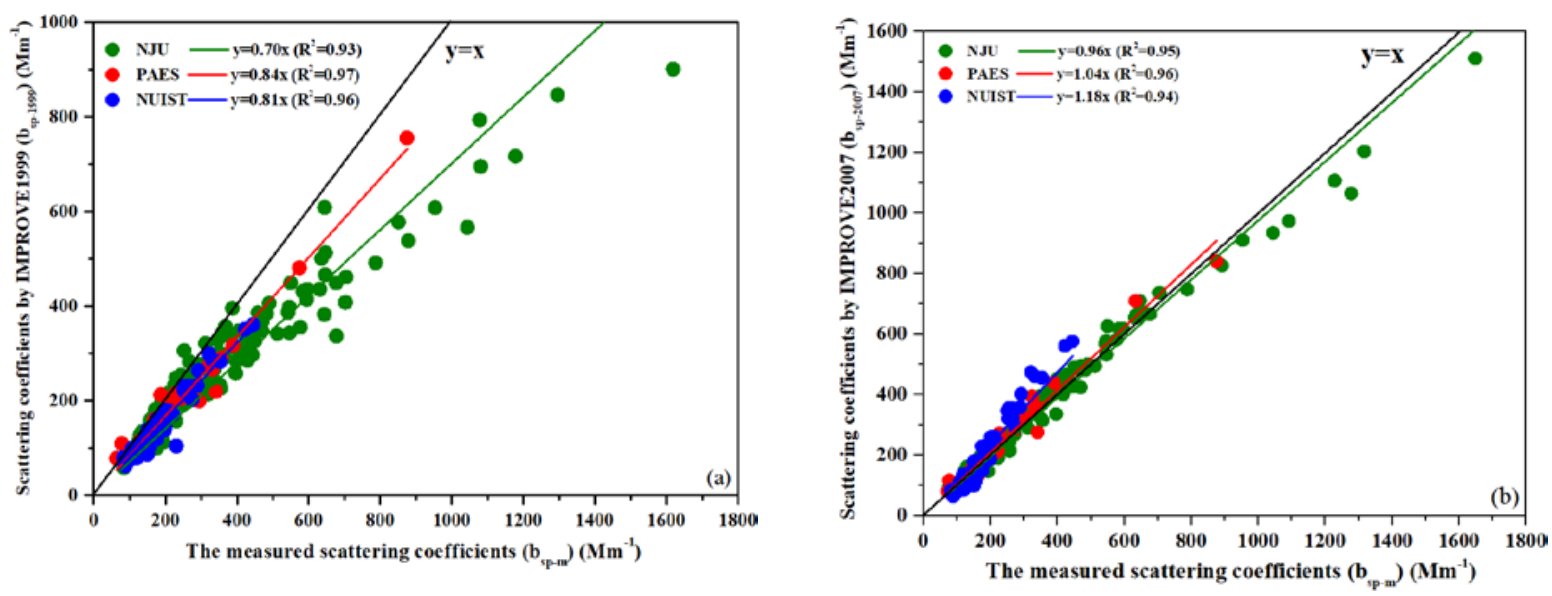

Figure S5. Linear regressions between the measured daily scattering coefficients and those calculated with the IMPROVE1999 algorithm (a) and the IMPROVE2007 algorithm (b) at the three sites. 

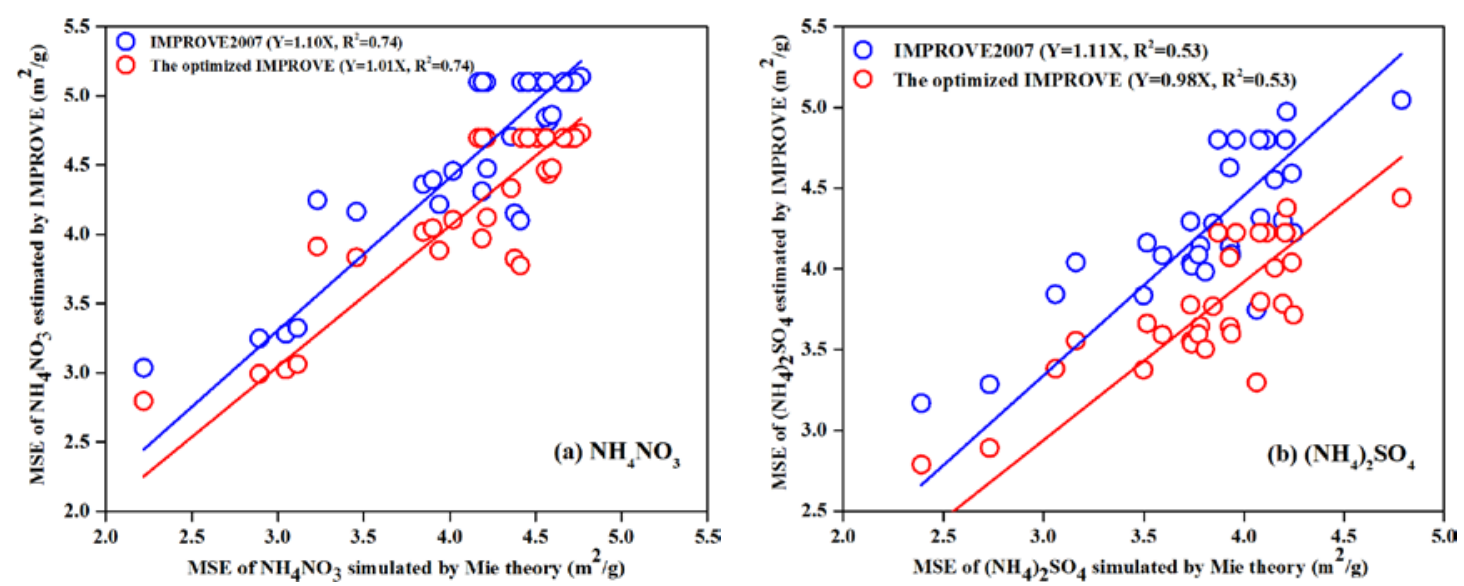

Figure S6. Linear regressions between the mass scattering efficiencies (MSE) of $\mathrm{NH}_{4} \mathrm{NO}_{3}(\mathrm{a})$ and $\left(\mathrm{NH}_{4}\right)_{2} \mathrm{SO}_{4}(\mathrm{~b})$ estimated with the Mie theory and those with the two version of US IMPROVE algorithms. 


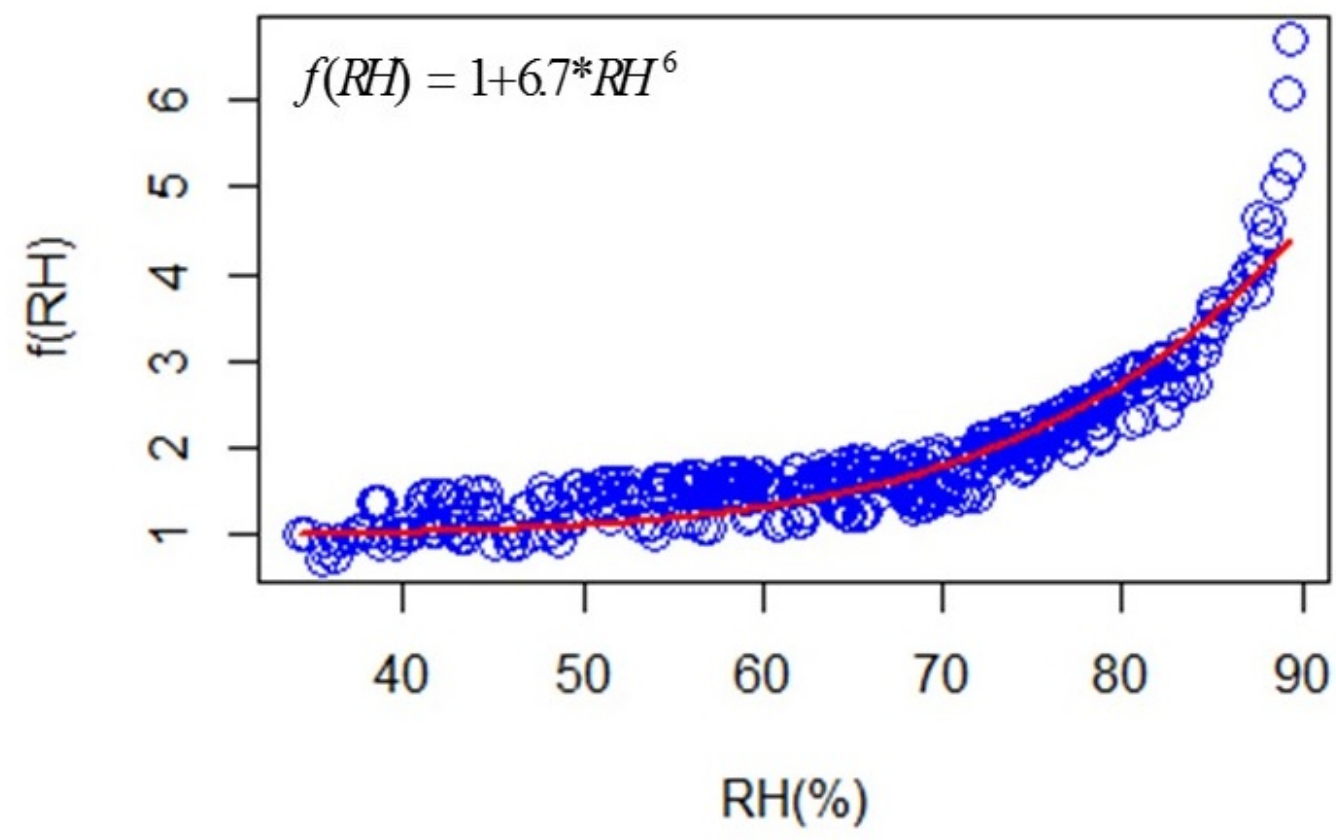

Figure S7. Hygroscopic growth curve of $\mathbf{P M}_{2.5}$ at NJU. 


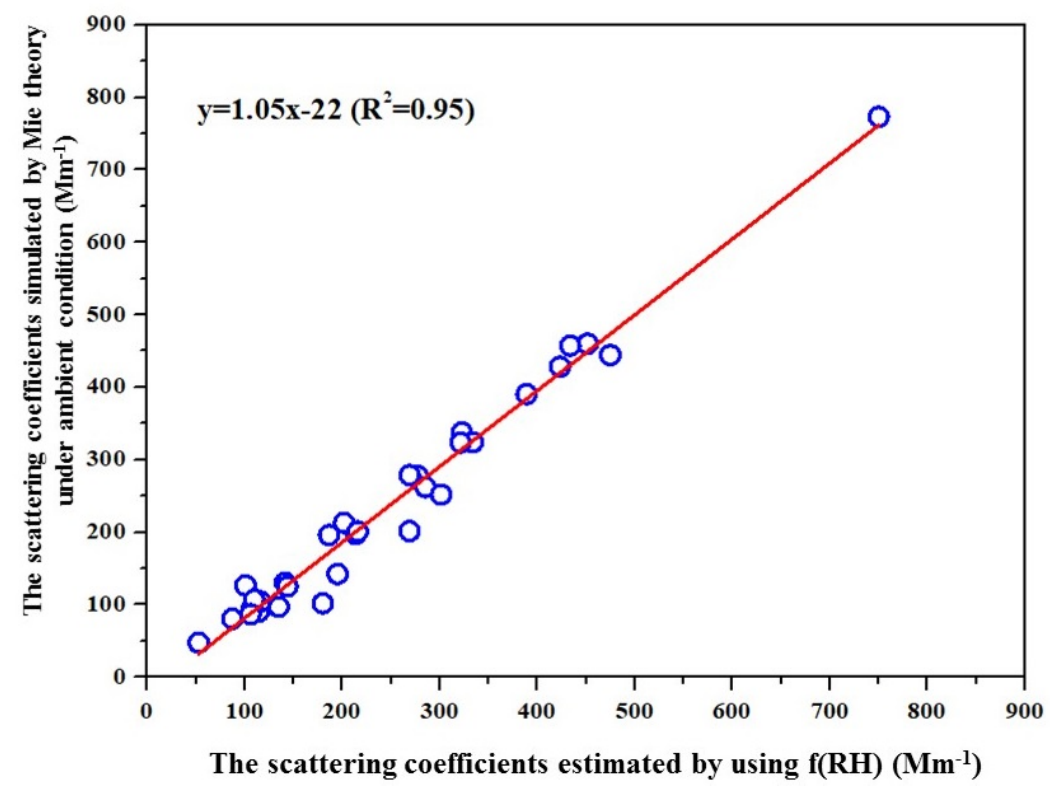

Figure S8. The correlation between the scattering coefficients estimated by $f(R H)$ and those simulated with Mie theory under the ambient conditions. 


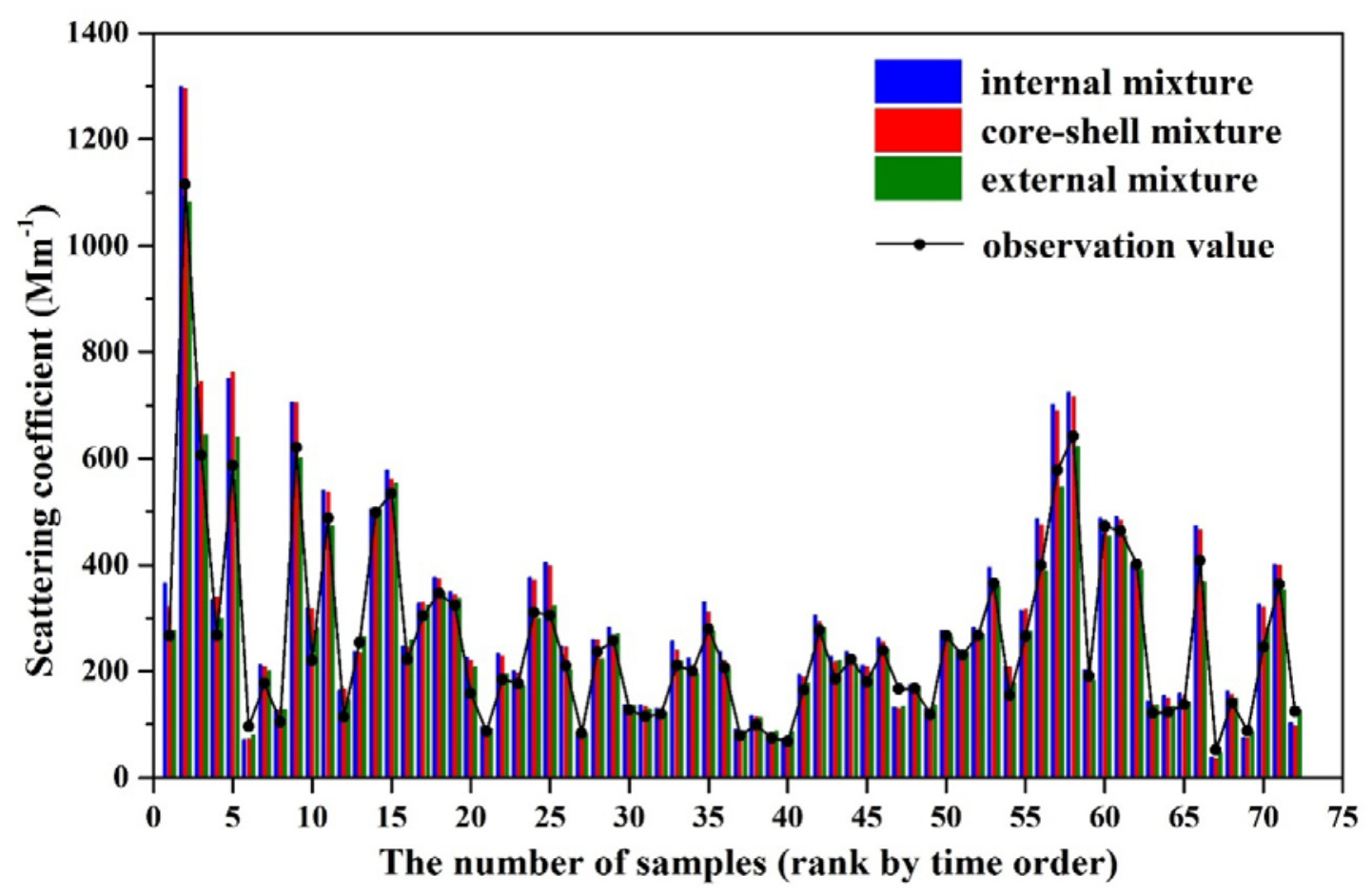

Figure S9. The comparison of the observed scattering coefficients and those estimated with the external, internal, core-shell mixture assumption under the ambient condition at $\mathrm{NJU}$. 


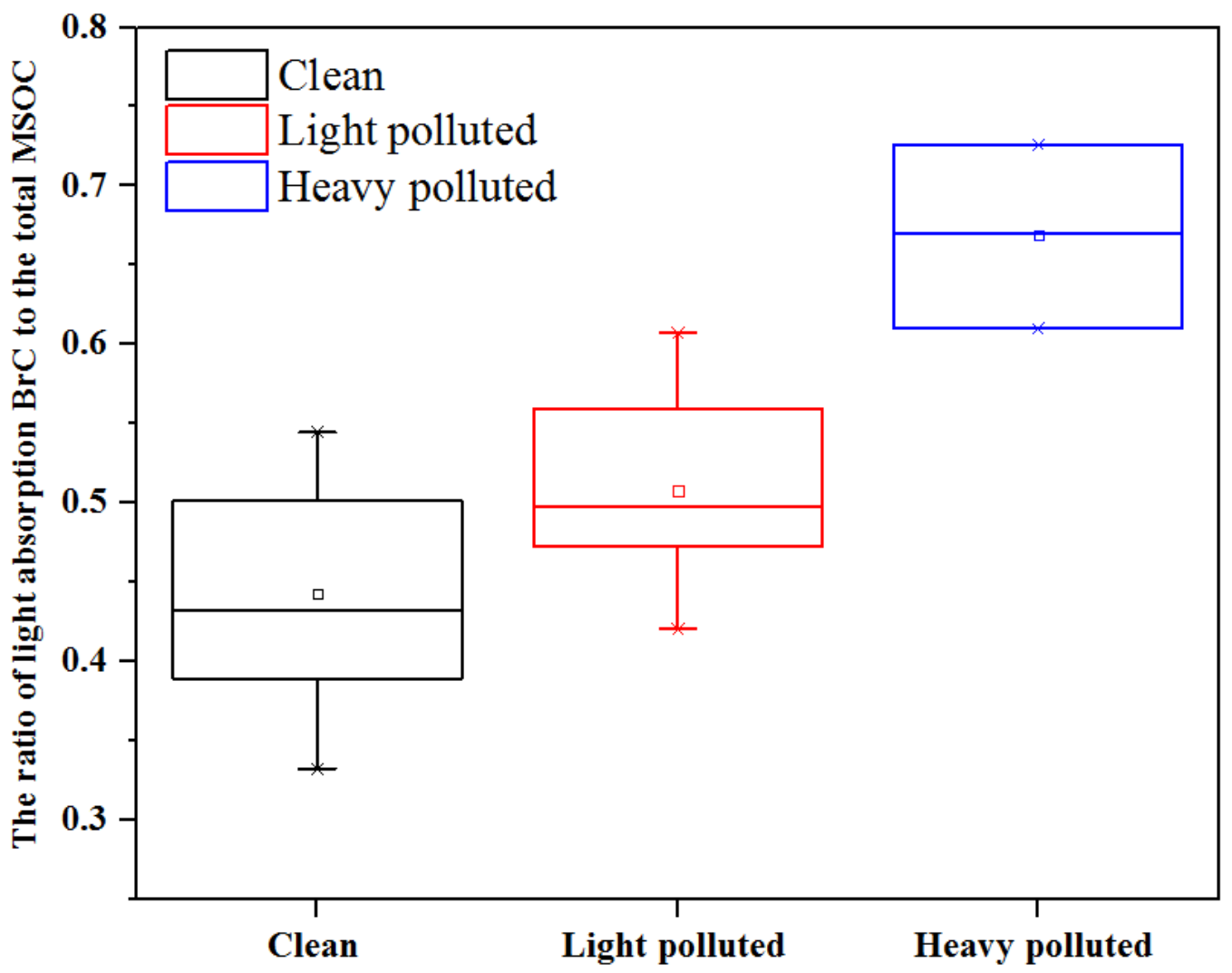

Figure S10. The box plots of the ratios of light absorption BrC mass to the total BrC mass under the three pollution levels. The box plots indicate the mean concentration (square symbols) and the maximum, 99th, 75th, 50th, 25th, 1st percentiles, and minimum. 


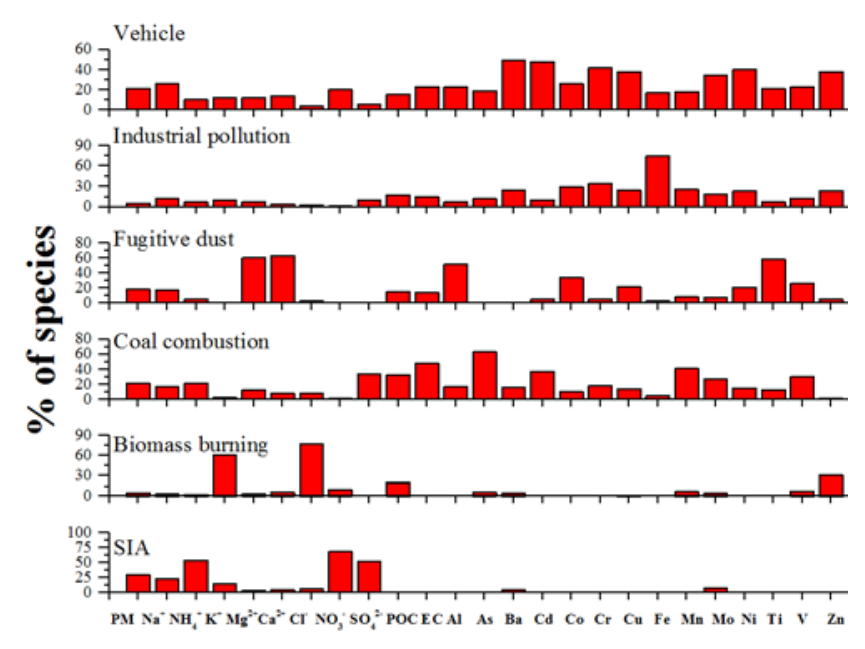

(a)

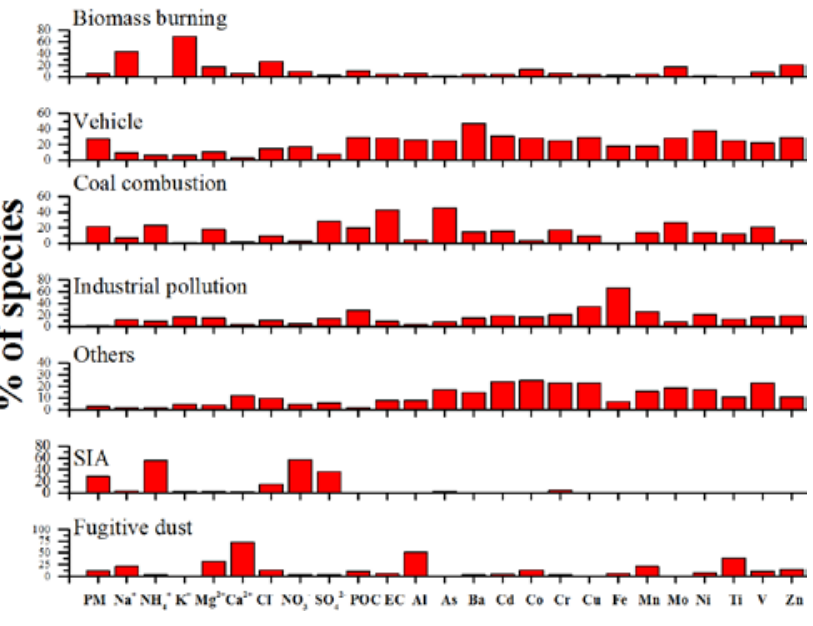

(b)

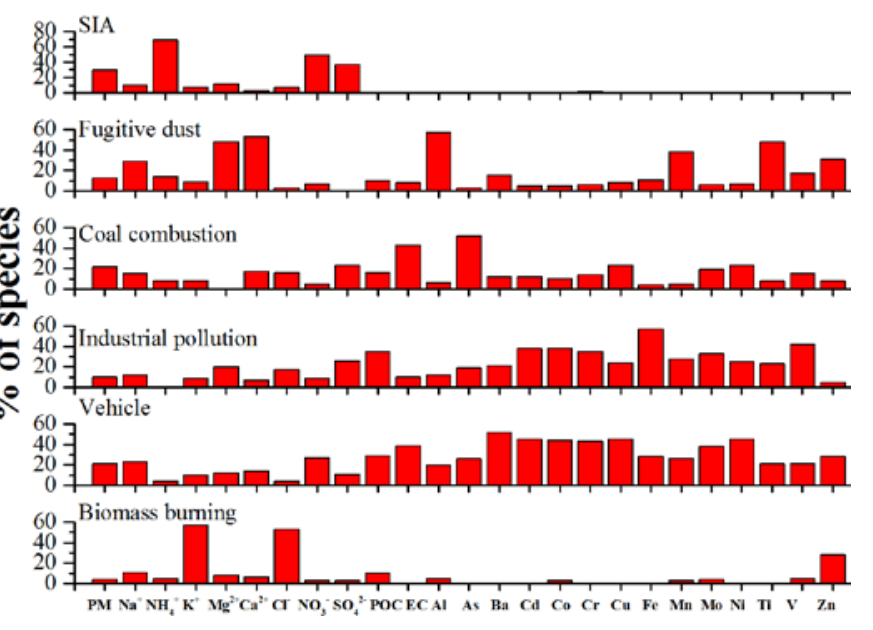

(c)

Figure S11. The source profiles for accumulation mode particles from the PMF model at NJU (a), PAES (b) and NUIST (c). 


\section{REFERENCES}

Li, Q., Yin, Y., Gu, X. S., Yuan, L., Kong, S. F., Jiang, Q., Chen, K., Li, L.: An observational study of aerosol hygroscopic growth factor and cloud condensation nuclei in Nanjing in summer, China Environ. Sci., 35, 337-346, 2015.

Pitchford, M., Malm, W., Schichtel, B., Kumar, N., Lowenthal, D., Hand, J.: Revised algorithm for estimating light extinction from IMPROVE particle speciation data, J. Air Waste Manag. Assoc., 57, 1326-1336, doi:10.3155/1047-3289.57.11.1326, 2007.

Wu, Y. X.: Observations of aerosol hygroscopic properties-Case study results over Mt. Huang and Nanjing, MA thesis, Nanjing University of Information Science \& Technology, 2014.

Xu, B., Zhang, Z. F., Li, Y. W., Qin, X., Miu, Q., Shen, Y.: Hygroscopic properties of aerosol particles in north suburb of Nanjing in spring. Environ. Sci., 36, 1911-1918, doi:10.13227/j.hjkx.2015.06.001, 2015.

Yu, X. N., Ma, J., Zhu, B., Wang, H. L., Yan, S. Q., Xia, H.: Effects of Relative Humidity and Aerosol Physicochemical Properties on Atmospheric Visibility in Northern Suburb of Nanjing, Environ. Sci., 36, 1919-1925, 2015.

Zhang, J., Wang, L., Chen, J. M., Feng, S. M., Shen, J. D., Jiao, L.: Hygroscopicity of ambient submicron particles in urban Hangzhou, China, Fron. of Environ. Sci. \& Engin. in China, 5, 342-347, 2011. 